\title{
РАСПРЕДЕЛЕНИЕ УРОВНЯ ГЛИКИРОВАННОГО ГЕМОГЛОБИНА У ЛИЦ С ВЫСОКИМ РИСКОМ РАЗВИТИЯ САХАРНОГО ДИАБЕТА 2 ТИПА И ПРЕДИАБЕТА НА ОСНОВАНИИ OПРОСНИКА FINDRISC
}

\author{
'Мельникова О.Г., ${ }^{1,2}$ Майоров А.Ю. \\ 'ФГБУ «НМИЦ эндокринологии» Минздрава России, Москва, Россия \\ ${ }^{2}$ ОООИ «Российская Диабетическая Ассочиачия», Москва, Россия
}

В настоящее время гликированный гемоглобин $\left(\mathrm{HbA}_{1 c}\right)$ рекомендуется не только для постановки диагноза, но и для выявления риска развития сахарного диабета. Учитывая стоимость исследования, необходимо выявление популяции с наиболее высоким риском нарушений углеводного обмена. Для это может быть использован валидированный опросник FINDRISC.

ЦЕЛЬ: изучение распределения уровня $\mathrm{HbA}_{1 с}$ у лиц с высоким риском развития сахарного диабета 2 типа и предиабета, выявленным на основании опросника FINDRISC.

МАТЕРИАЛЫ И МЕТОДЫ: пилотнЫЙ проект «Предиабет - время действовать» проводился в 2018-2019 гг. при поддержке ООО «Мерк» и ОООИ «Российская диабетическая ассоциация». Опросник для выявления риска развития сахарного диабета 2 типа и предиабета FINDRISC был размещен в сети Интернет. В 18 пилотных регионах Российской Федерации (Алтайский край, Республика Башкортостан, Белгородская область, Волгоградская область, Воронежская область, Иркутская область, Краснодарский край, Курская область, Нижегородская область, Новосибирская область, Омская область, Приморский край, Ростовская область, Самарская область, Свердловская область, Республика Татарстан, Хабаровский край, Челябинская область) была проведена рекламная кампания для населения в СМИ, социальных сетях, поисковых системах GOOGLE и YANDEX, а также среди врачей общей практики и терапевтов о том, кому и как следует заполнить опросник. Также можно было заполнить этот опросник во время приема у врача общей практики или терапевта. Если человек при заполнении опросника набрал 12 и более баллов, он получал рекомендацию и возможность сдать бесплатно анализ крови для определения $\mathrm{Hb} \mathrm{Ac}_{1 c} \mathrm{~B}$ лаборатории INVITRO. В случае если $\mathrm{HbA}_{1 с}$ был менее $6 \%$, человеку давались общие рекомендации по регулярному обследованию в рамках диспансеризации. Если $\mathrm{HbA}_{1 с}$ был 6,0-6,4\%, то давалась рекомендация провести дальнейшее дообследование у врача общей практики. Если $\mathrm{HbA}_{1 с}$ был 6,5\% и выше, то давалась рекомендации обратиться к эндокринологу.

PEЗУЛЬTATЫ: 59983 человека заполнили опросник FINDRISC, среди них 32391 набрали 12 и более баллов. Результаты определения $\mathrm{HbA}_{1 c}$ получены для 20150 человек. В исследуемой выборке соотношение

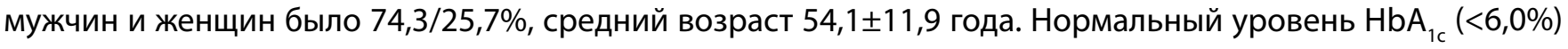
имели 13308 человек (66,0\%), от 6,0 до 6,4\% - 2829 (14,0\%), 6,5\% и выше (явный сахарный диабет) 4013 (20,0\%). Было показано, что в последней группе пациентов с фактически установленным сахарным диабетом 1184 (5,9\%) имели $\mathrm{HbA}_{1 с}$ от 6,5 до 6,9\%, 663 (3,3\%) - от 7,0 до 7,4\%, 497 (2,5\%) - от 7,5 до 7,9\%, 648 (3,2\%) - от 8,0 до 8,9\%, 1021 (5,1\%) - 9,0\% и выше. Таким образом, значительная доля лиц с впервые выявленным сахарным диабетом находилась в состоянии выраженной метаболической декомпенсации.

Выводы: на основании оценки распределения уровня $\mathrm{HbA}_{1 с}$ можно сделать вывод, что опросник FINDRISC является надежным инструментом для выявления сахарного диабета 2 типа. Для уменьшения затрат на лабораторные исследования опросник FINDRISC должен быть использован в широкой клинической практике у врачей всех специальностей для предварительного отбора на скрининг. Использование интернет-ресурса значительно расширяет и упрощает возможности диагностики нарушений углеводного обмена.

КЛЮЧЕВЫЕ СЛОВА: сахарный диабет; предиабет; FINDRISC; HbА 